\title{
Discussion on Business Mode of Biogas Industry in Beijing
}

\author{
Hui-zhi ZHANG* \\ Institute of Agricultural Scientech Information \\ Beijing Academy of Agriculture and Forestry Sciences \\ Beijing, 100097, China \\ e-mail: zhanghuizhi@sina.com \\ Pan-pan YANG \\ Institute of Agricultural Scientech Information \\ Beijing Academy of Agriculture and Forestry Sciences \\ Beijing, 100097, China
}

\author{
Lei CHEN \\ Institute of Agricultural Scientech Information \\ Beijing Academy of Agriculture and Forestry Sciences \\ Beijing, 100097, China \\ Bao-rong HUANG \\ Institute of policy and management \\ Chinese Academy of Sciences \\ Beijing, 100190, China \\ e-mail: huangbaorong@casipm.ac.cn
}

\begin{abstract}
Large and medium scale biogas project has become the primary form in the development of biogas industry in Beijing. Based on the survey of biogas projects in Beijing, the characteristics of production mode and business operation mode of biogas industry are summarized. There are four production modes in Beijing: biogas-heat-electricity-fertilizer co-production mode, biogas-fertilizer co-production mode, multi-village combined biogas supply mode and Agri-ecological farm mode. And there are also four business operation modes in Beijing: local village committee management mode, village professional team management mode, local village committee and enterprise co-management mode and enterprise management mode. The mode of biogas-fertilizer coproduction and village professional team management offer more benefits than other biogas projects in Beijing.
\end{abstract}

Keywords-Biogas project; Production mode; Operation model; Cost-benefit analysis

\section{INTRODUCTION}

With years of development, business operation of biogas industry in the world has formed a variety of models, especially in Europe and America. Combined-heat-and-power mode (CHP) was mainly applied in Germany, Britain, Denmark, Australia, Span, Netherlands and America. The mode compressed natural gas $(\mathrm{CNG})$ for vehicles was mainly applied in Sweden and Switzerland. Pipeline-natural-gas mode was mainly applied in Germany, Sweden, Switzerland and France [1,2]. Biogas industry in China started in the early 1960s and has been gradually developed from household digester to medium and large-size biogas project. Until to the end of 2010 , more than 50 thousand medium and large-size biogas projects had been built and more than 16 billion $\mathrm{m} 3$ biogas were produced per year in China. Household biogas and village-scale centralized biogas supply are the primary biogas utilization mode in China now. Although there are many pilot project of biogas-electricity mode and biogas-fertilizer coproduction mode in China, biogas industrialization and matured business mode weren't formed. Biogas stations have to rely on government financial subsidies to maintain the cost of the daily operation. Despite the rapid increase in biogas production, more business mode and biogas derivative product are need to promote the development of biogas industry.

Biogas industry in Beijing develops rapidly since 2000 . There are more than 100 biogas projects at the end of 2014, in which 15 projects have the daily biogas production capacity of more than $500 \mathrm{~m}^{3}$. Large and medium scale biogas project has become the primary form in Beijing. Biogas project significantly changes the energy structure in rural areas in Beijing and plays an important role in the development of local circular economy. Depended on the raw materials, production process and technology, source of construction fund, business management and other factors, a variety of production and business models of biogas are formed in Beijing. A survey was carried out on the biogas projects in Beijing by Beijing Municipal Bureau of Agriculture in 2014. Based on these survey data, production mode and business operation mode will be discussed to find out the actual operational condition of biogas projects in Beijing.

\section{PRODUCTION MODE OF BIOGAS PROJECTS IN BEIJING}

Four primary biogas production modes, Biogas-heat-electricity-fertilizer co-production mode, biogas-fertilizer co-production mode, multi-village combined biogas supply mode and Agri-ecological farm mode, will be discussed here.

\section{A. Biogas-heat-electricity-fertilizer Co-production Mode}

Beijing Deqingyuan (DQY) biogas project is the largest agricultural Clean Development Mechanism project in China. Biogas-heat-electricity-fertilizer co-production mode is applied in DQY biogas project. In 2007, a biogas station was built to produce heat and electricity using chicken manure as raw material. And another biogas station was built to produce domestic compressed natural gas (CNG) in 2012. A green development mode from chicken manure to biogas, electricity, heat and fertilizer is formed in DQY now. The 
project supplies 14 million kwh of electricity to the State Grid and 2.76 million $\mathrm{m}^{3} \mathrm{CNG}$ to more than 10 thousand local rural families for household energy each year. Thermal energy equivalent to 4500 tons of standard coal is recycled by heat-recovering system and up to 84000 tons of carbon dioxide are saved annually. Meanwhile, DQY is looking for the development channels of CNG for vehicle energy supply and other commercial purpose of biogas utilization in the future.

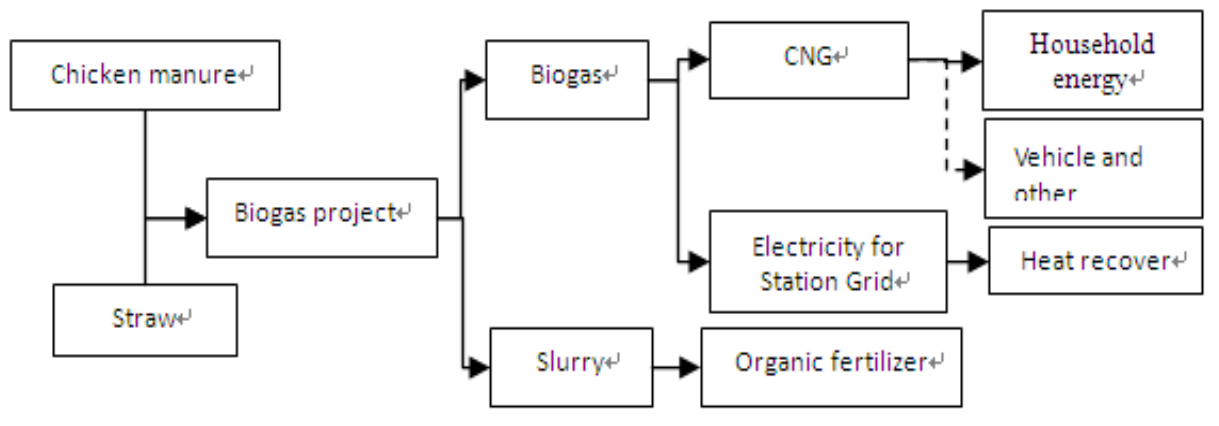

Figure 1. Diagram of biogas-heat-electricity-fertilizer co-production mode in DQY

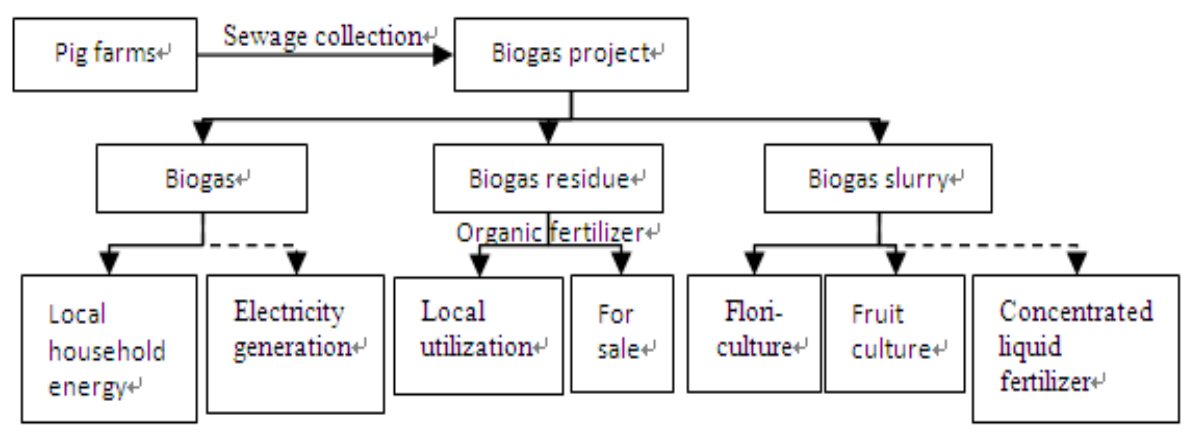

Figure 2. Diagram of biogas-fertilizer co-production mode in Beilangzhong and Xibaidian

\section{B. Biogas-fertilizer co-production Mode}

Biogas fertilizer co-production mode is very common in Beijing. Biogas projects in Beilangzhong and Xibaidian are the typical case of this mode. In Beilangzhong, a biogas project with daily production capacity of $2200 \mathrm{~m}^{3}$ biogas and an organic fertilizer plant with annual production capacity of 20000 tons of organic fertilizer are built in 2002. The output of organic fertilizer effectively improves the economic benefits of the project. In Xibaidian, a biogas project with daily production capacity of $2020 \mathrm{~m}^{3}$ biogas and an organic fertilizer plant with annual production capacity of 20000 tons of organic fertilizer are built. Biogas project links planting, livestock breeding and energy circulation together and a virtuous circle of ecological and economic system is formed in the village.

\section{Multi Village Combined Biogas Supply Mode}

Liuminying is the first place to implement the research of ecological agriculture in China. Biogas project as a link of agricultural waste resource utilization has gone through more than 30 years with total investment of 23.8 million Yuan. The project is completed in three phases with total biogas production capacity of $1900 \mathrm{~m}^{3} / \mathrm{d} .90 \mathrm{~km}$ biogas transmission and distribution pipeline is built to supply biogas for Liuminying and six surrounding villages. 1690 households in these seven villages are benefited from the biogas project. After a simple treatment, the biogas residue and slurry are returned back to the field as fertilizer. After years of construction, a circular agriculture model of "Breeding-biogas-vegetable-farmer" is formed and the utilization rate of agricultural waste resource increases greatly in Liuminying. Future production and application of concentrated liquid fertilizer, leaf fertilizer, plant nutrient solution, plant culture substrates and other fertilizers products are being planned. 


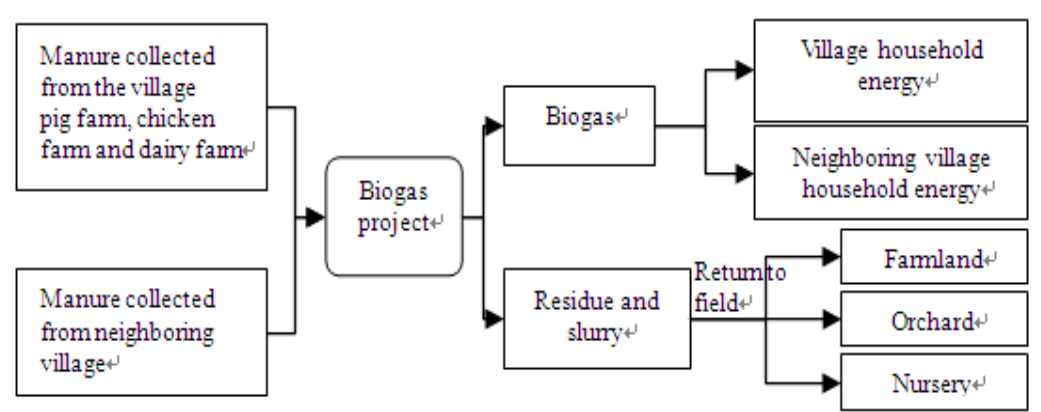

Figure 3. Diagram of multi-village combined biogas supply mode in Liuminying

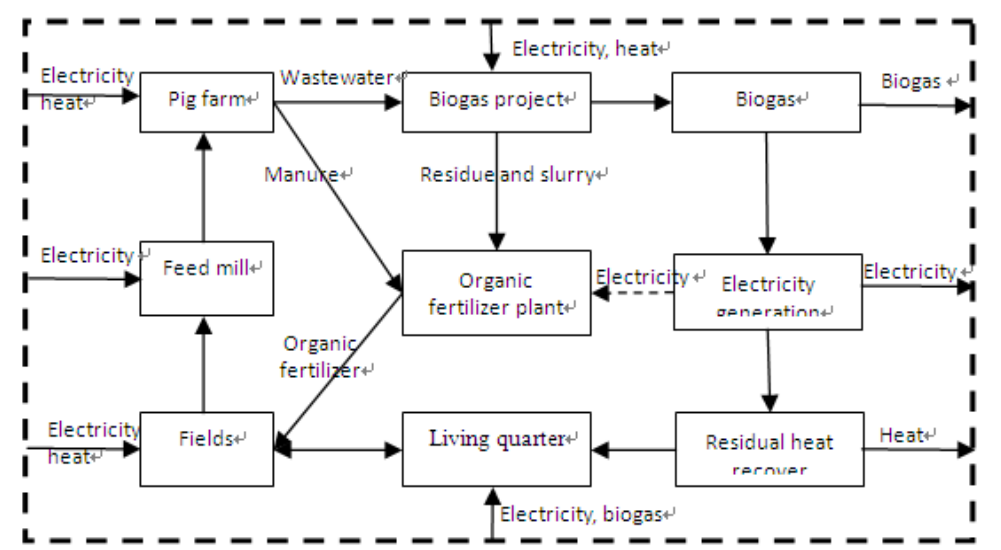

Figure 4. Diagram of agri-ecological farm mode in Austrian

\section{Agri-ecological Farm Mode}

In Beijing Austrian Agriculture Company, based on the large-scale pig farm and 300 acres of greenhouse vegetable planting base, a biogas project is constructed, with an annual output of 10 million $\mathrm{m}^{3}$ of biogas, 1 million tons of liquid organic fertilizer and 2000 tons of solid organic fertilizer. Using biogas project as the link, biogas-electricity-thermal-energy-cycle conversion and utilization mode is established in Austrian. Integrated ecological pig breeding, biogas production, organic fertilizer production and vegetable planting technology, the ecosystem of pig-biogas-fertilizer-vegetable is formed. Now Austrian is a circular agriculture ecological park and a modern agricultural demonstration park. The goals of zero emission of pollutants and recycling of resources and energy are achieved in the park.

\section{BUSINESS OPERATION MODE OF BIOGAS PROJECTS IN BEIJING}

In the production and operation of biogas projects, a good business management is more important than a series of high quality infrastructures and equipments. Survey reveals that most of the biogas projects in Beijing are in poor management. It is necessary to figure out where the problem is. In the investigation, there are four primary business operation modes in Beijing: local village committee management mode, village professional team management mode, local village committee and enterprise co-management mode and enterprise management mode (Table 1).

TABLE I. THE OPERATION MODE OF BIOGAS PROJECTS AND ITS TYPICAL CASE IN BEIJING

\begin{tabular}{|c|c|c|}
\hline & Business operation mode & Typical biogas project \\
\hline I & $\begin{array}{l}\text { Local village committee } \\
\text { management }\end{array}$ & Most biogas projects \\
\hline II & $\begin{array}{c}\text { Village professional team } \\
\text { management }\end{array}$ & $\begin{array}{l}\text { Biogas project in } \\
\text { Beilangzhong, Liumingying } \\
\text { and Lianghe }\end{array}$ \\
\hline III & $\begin{array}{l}\text { Local village committee and } \\
\text { enterprise co-management }\end{array}$ & $\begin{array}{l}\text { Biogas project in Doudian, } \\
\text { Daciluo, Wuzi and Xiacun. }\end{array}$ \\
\hline IV & Enterprise management & $\begin{array}{c}\text { Biogas project in Deqingyuan, } \\
\text { Yanling and Austrian. }\end{array}$ \\
\hline
\end{tabular}

A. Local Village Committee Management

The biogas project managed by the village committee is generally the energy and ecological balance project, which is invested by the government. The management team consists of 1 administrator (which is generally the member of village 
committee) and 1 3 trained technical workers (which is generally villagers). The running cost of the biogas project comes from the biogas sales income, the government subsidy and the village collective economic subsidy. Survey shows that most of these biogas station cannot be responsible for their own profits and losses.

\section{B. Village Professional Team Management}

Under the village professional team management mode, government invests in the construction of biogas project, and then delivers the project to the village committee. Village committee commissioned a professional management team to carry out the operation and management of the biogas project. Independent economic accounting is implemented in the management of biogas project. Biogas projects in Beilangzong, Lijiayu, Liuminying and Lianghe village are all belong to this type.

\section{Local Village Committee and Enterprise Co-Management}

In the co-management mode, biogas projects are generally invested by local government, or the joint venture of government and village. Generally, two types of management are implemented: First, village committee manages biogas project and sets up the management team which is composed of village committee members, villagers and enterprise technicians. Village manager is responsible for daily management, enterprise technicians and villagers are responsible for the production of biogas. Village committee pays cooperation fees to enterprise. Second, after the signing of management trust agreement between village committee and enterprise, enterprises responsible for the biogas production, sale, security guarantee and stable operation of biogas project.

\section{Enterprise Management}

Biogas projects are invested and built by enterprises, or the government and enterprises to jointly invest in the construction. Biogas project is managed and operated by enterprise independently. Local government supplies appropriate project maintenance financial subsidies to enterprises. Enterprises assume sole responsibility for their profits or losses in the management of biogas project.

\section{CONCLUSION}

Four production modes and four business operation modes of biogas project in Beijing are discussed. According to the survey and cost-benefit analysis, Beilangzhong biogas project achieves more economic benefits than other biogas projects. The mode of biogas-fertilizer coproduction and village professional team management mode offers wide applicable values in Beijing.

\section{ACKNOWLEDGMENT}

This work is supported by Science and Technology Planning Project of Beijing (D141100001214001).

Work partially supported by Science Foundation for Young Researchers of Beijing Academy of Agriculture and Forestry Sciences (QNJJ2014-24).

\section{REFERENCES}

[1] X.Y. Jiang, S. G. Sommer and K.V. Christensen, A review of the biogas industry in China, Energy Policy 39, 6073-6081 (2011).

[2] J. Gosens, Y.L. Lu, G.Z. He, et al., Sustainability effects of household-scale biogas in rural China, Energy Policy 54, 273-287 (2013).

[3] W.Qu, Q. Tu and B. Bluemling, Which factors are effective for farmers' biogas use? - Evidence from a large-scale survey in China, Energy Policy 63, 26-33(2013). 